\title{
OPTICAL MICROSCOPY AS A SIMPLE METHOD FOR ANALYSIS OF BOILER TUBE FAILURE
}

\author{
Milan T. Jovanović, Zoran Mišković, Vesna Maksimović, Ivana Cvijović-Alagić \\ ${ }^{1}$ Department of Materials Science, Institute of Nuclear Sciences "Vinča", \\ University of Belgrade, POB 522, 11001 Belgrade, Serbia
}

Received 10.12.2019

Accepted 01.01.2020

\begin{abstract}
A severely damaged low carbon steel boiler tube was the object of this investigation. Detailed microstructural characterization was performed by optical microscopy, whereas scanning electron microscopy (SEM) was applied only in a few cases. Results show that a variety of microstructures was formed in the material of the damaged boiler tube during its exploitation. The failure of the tube is the result of very inhomogeneous overheating. The side of the boiler tube toward fire $(\mathbf{F})$ was exposed to high overheating temperature, which in some locations was well above the $A_{3}$ transformation temperature. The side toward boiler $(\mathbf{B L})$ was subjected to lower temperatures, i.e. in the region mostly between $\mathrm{A}_{1}$ and $\mathrm{A}_{3}$ temperatures. Variations in temperatures and cooling rates, which resulted in microstructural inhomogeneity, are the main cause for the formation and multiplication of stresses leading to the rupture of the tube.
\end{abstract} Failure.

Keywords: Boiler tube; Austenite; Bainite; Widmanstätten ferrite; Overheating;

\section{Introduction}

The boiler tubes, designed to be exploited for a long period, operate in complex conditions involving high temperature, pressure and corrosive environment. One or more of these mechanisms are responsible for microstructural changes causing failure of the tubes. The failure of the tubes occurs when the effective strength, i.e., the load-bearing capacity of the tubes, falls below a critical level determined by component geometry and strength of the material [1]. Avoidance of such failure is of great importance since the failure results in a shortage of electric power and loss of industrial production.

Boilers and other types of steam-power plant equipment are subject to a wide variety of failures involving one or more of several mechanisms [2]. Overheating is one

*Corresponding author: Milan T. Jovanović, tmsjovanovic39@gmail.com 
of the main causes of the failure of boiler tubes. Approximately $39 \%$ of boiler tube failures are related to overheating [3]. Fatigue and corrosion fatigue are listed as the next common cause of failure. Hydrogen damage of boiler tubes is caused by a corrosive reaction between steam or cooling water and steel:

$$
3 \mathrm{Fe}+4 \mathrm{H}_{2} \mathrm{O}=\mathrm{Fe}_{3} \mathrm{O}_{4}+8 \mathrm{H}
$$

The precipitation of molecular hydrogen (or methane), according to relation:

$$
4 \mathrm{H}^{+}+\mathrm{Fe}_{3} \mathrm{C}=3 \mathrm{Fe}+\mathrm{CH}_{4}
$$

occurs along grain boundaries, causing decarburization [4]. Tubes that have undergone this type of damage show a characteristic „window" fracture, in which the portion of the tube was detached [5].

This investigation aimed to perform the microstructural characterization of the ruptured boiler tube. The idea was to provide results and discussion, which might serve not only as of the basis for creating a clearer picture of the causes involved in failures of the boiler tubes but also in preventing these failures.

\section{Material and methods}

Brand DIN 15Mo3 (seamless tubes for service at elevated temperatures, JUS Standard, steel mark C.B.5.022) corresponds most closely to the low carbon steel structure. According to the spectrophotometric analysis the chemical composition (in wt.\%) of the boiler tube was as follows: $0.12 \mathrm{C}, 0.38 \mathrm{Si}, 0.90 \mathrm{Mn}, 0.05 \mathrm{P}, 0.014 \mathrm{~S}, 0.04 \mathrm{Cr}$, $0.02 \mathrm{Ni}, 0.45 \mathrm{Mo}$.

The method of optical microscopy (optical microscope "Reichert") was used for microstructural examinations. Metallographic preparation was carried out using the standard procedure, i.e. grinding and polishing. Microstructural examinations were performed on both polished samples (without previous etching), and samples etched after previous polishing. A $1 \%$ solution of nitric acid in alcohol ("Nital") was used for etching. Scanning electron microscope (SEM) "JEOL JSM 5800LV" was used to a very limited extent. Vickers macrohardness measurements were performed using the "Carl Franck" hardness-tester with an applied load of $5 \mathrm{~kg}$ and $20 \mathrm{~s}$ dwelling time.

\section{Results and discussion}

Visual inspection

The tube has suffered significant damage (Fig. 1). This type of damage is known as a "window" fracture.

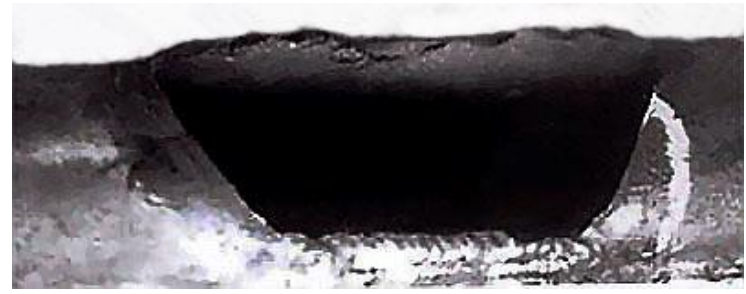

Fig. 1 Damaged boiler tube showing a "window" fracture. 
By observing the cross-section of the tube, it can easily be seen that half of the cross-section of the tube segment facing the fire (hereinafter referred to as $\mathbf{F}$ ) was thinner than the part facing the wall of the boiler (marked as BL). The measured thickness of the tube walls at different cross-sectional areas is shown in Figure 2.

TO BOILER
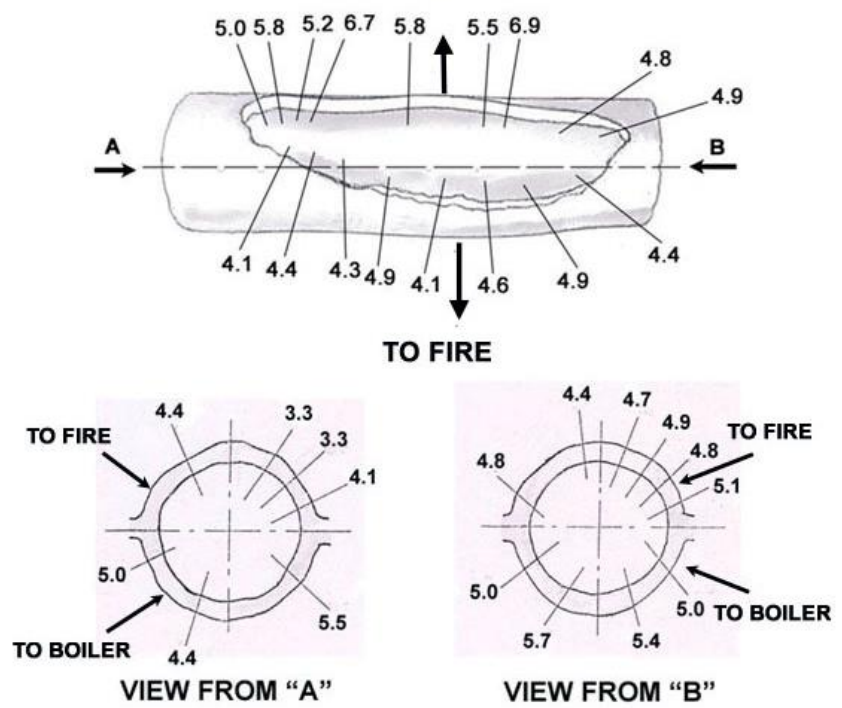

Fig. 2. The thickness of the tube walls at different cross-sectional areas.

The results of these measurements show that the wall of side $\mathbf{F}$ is thinner than that of side BL. Erosion and corrosion are mechanisms that can cause thinning and subsequent rupture. Overheating may or may not occur in tubes thinned by erosion and corrosion [5].

The outer and inner walls of the tube are covered with oxide layers. The oxide layers of the inner wall of $\mathbf{F}$ and $\mathbf{B L}$ sides are partially scaled and fell off from the wall as opposed to the compact coating on the outer wall of the tube.

The fractured tube walls are flat, with sharp edges, and also covered with oxides. Side $\mathbf{F}$ is slightly swollen in a direction to the fracture.

\section{Method of sampling and marking for microstructural investigation}

The method of cutting and marking of samples for microstructural examination is shown schematically in Figure 3a. Also, a schematic presentation of the cross-section of segment $\mathbf{A}$ with marked sections of individual samples is presented in Figure 3b. Sections from 1-4A (toward fire F) and 5-7A (toward boiler BL) indicate the locations on the cross-section of the segment that were examined using an optical microscope. 


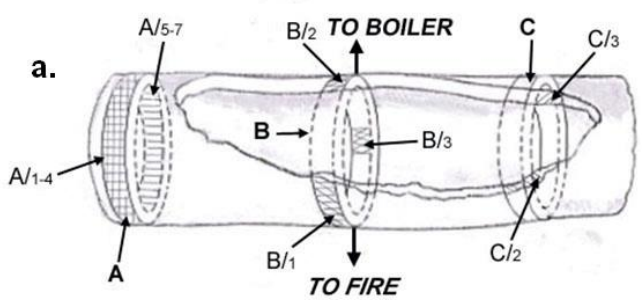

(a)

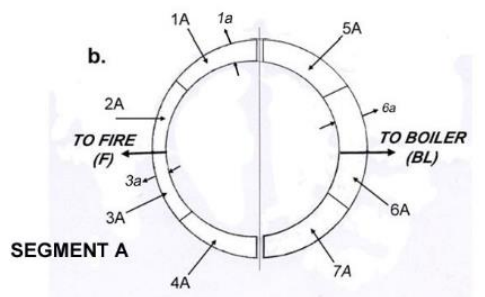

(b)

Fig. 3. a. Method of sampling and marking for microstructural examinations; b. schematic presentation of a cross-section of segment $\boldsymbol{A}$ with marked sections: section $\mathbf{1 a}$ (non-etched oxide layer); sections $\mathbf{3} \boldsymbol{a}$ and $\mathbf{6} \boldsymbol{a}$ (etched oxide layer).

Metallographic characterization of segment $\boldsymbol{A}$ in non-etched condition

The sample corresponding to section 1a (in Fig. 3b) was only polished (Fig. 4). Oxide layers on the outer and inner part of the side $\mathbf{F}$ are clearly visible. The thickness of the oxide layer of the outer surface is much higher (approximately $200 \mu \mathrm{m}$ ) than that of the inner part of the tube (less than $30 \mu \mathrm{m}$ ). This thinning is ascribed to scaling and falling off the oxide due to erosion by cooling water. Inclusions may be seen in the space between the outer and inner walls of the tube.

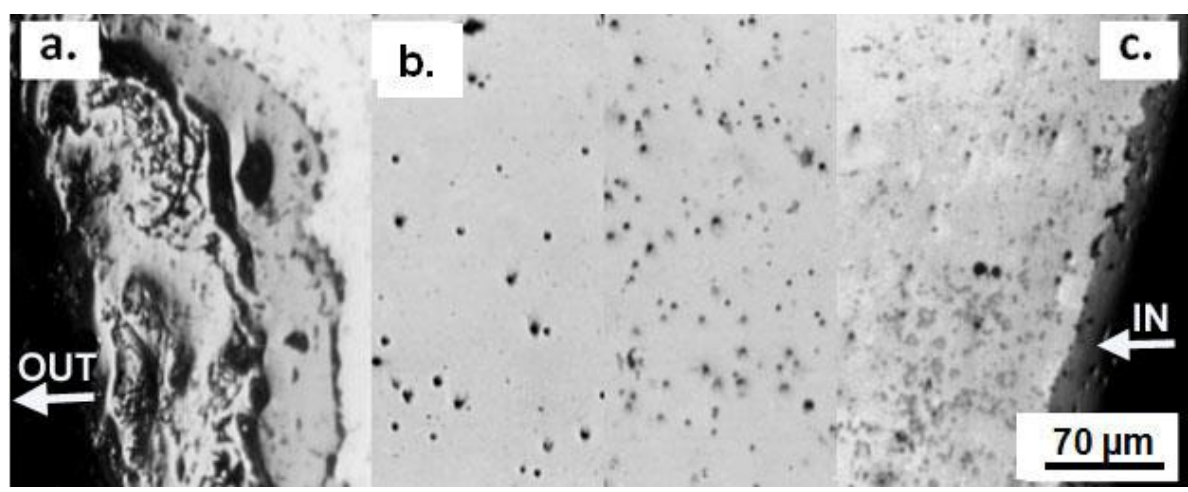

Fig. 4 Non-etched sample. Oxide layers of section 1a, side F; (marked in Fig 3b); a. Outer wall; $b$. interior part; $c$. inner wall. 
Observation of oxide layer after etching

Oxide layers after etching of $\mathbf{F}$ and BL sides (sections 3a and $\mathbf{6 a}$ in Fig. 3b) are illustrated in Figure 5a-d.

Following the visual inspection, dents and holes may be seen on the inner wall of both $\mathbf{F}$ and BL sides (Fig. 5b, c). These defects appeared as a consequence of the scaling and dropping of oxide debris. A portion of the inner wall of side $\mathbf{F}$ has a sporadic sawlike shape, which is seen in Figure 5b. It was difficult to detect the presence of oxide on this section of the wall, which indicates that the oxide layer has been removed by erosion. As a result of corrosion, an oxide strip of width between 30 and $70 \mu \mathrm{m}$ is detached from the surface of the inner wall of side BL (Fig. 5c). The outer walls of both sides are covered with an oxide layer and its thickness varies between 5 and $25 \mu \mathrm{m}$ (side BL) and 10 to $40 \mu \mathrm{m}$ (side F). The oxide layer of the outer wall of side BL (Fig. 5d) is more compact and uniform than the corresponding oxide layer of side $\mathbf{F}$ (Fig. 5a). Comparing oxide thickness and morphology from different sections of the tube walls (Figs. 4 and 5) it follows that oxide layers are nonhomogeneous varying in the wide range of thickness. These results also indicate that side $\mathbf{F}$, being exposed to a higher temperature, was more prone to oxidation and corrosion processes.
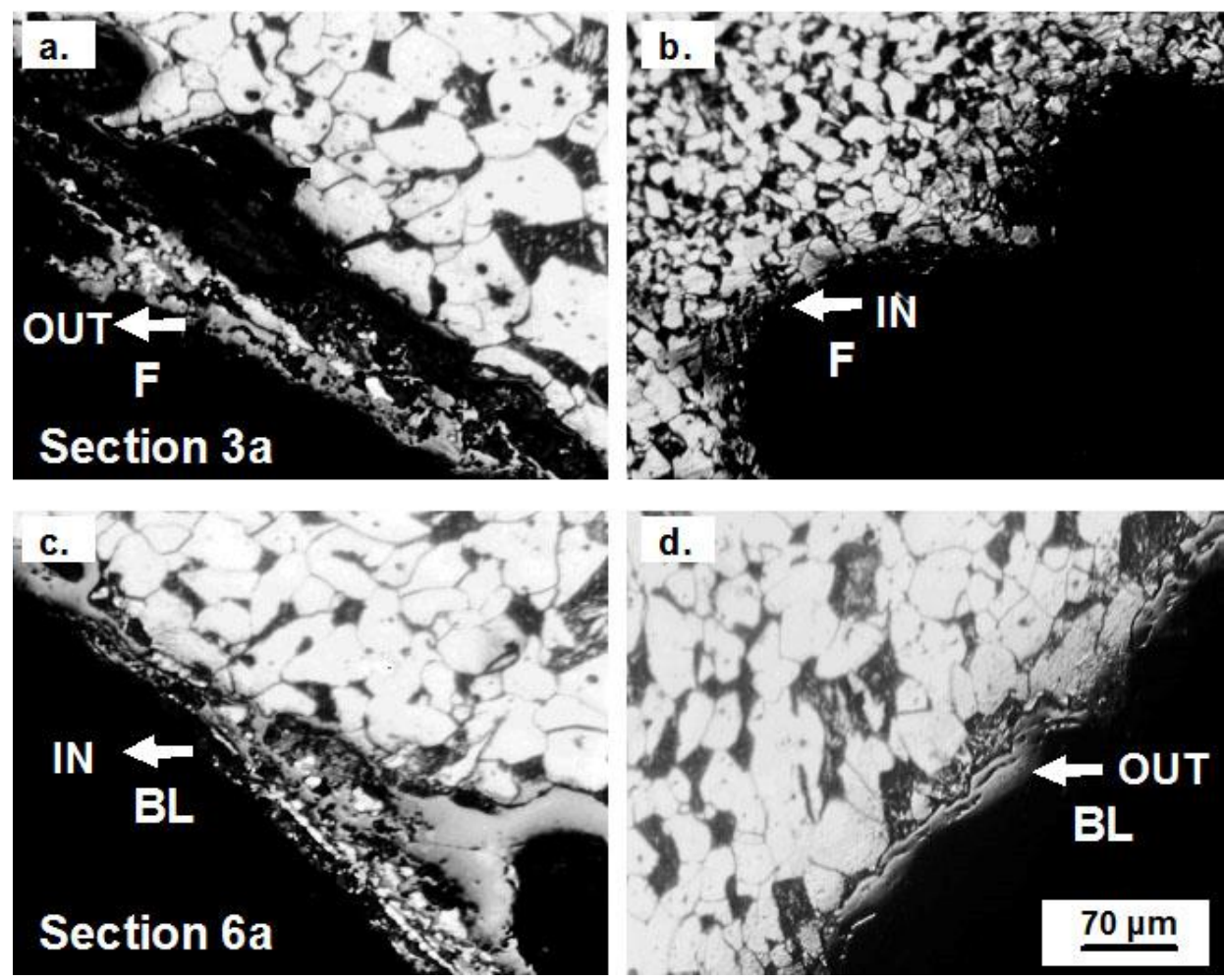

Fig. 5. Etched samples. Oxide layers of sections $\mathbf{3 a}$ and $\mathbf{6} \boldsymbol{a}$ (marked in Fig. 3b); OUT and IN denote outer and inner walls of $\boldsymbol{F}$ and $\boldsymbol{B L}$ sides. 
Microstructural investigation of segment $\boldsymbol{A}$

Figure 6(a-f) illustrates microstructural characteristics of side $\mathbf{F}$ of the segment $\mathbf{A}$. Rather heterogeneous structure may be seen in these micrographs.
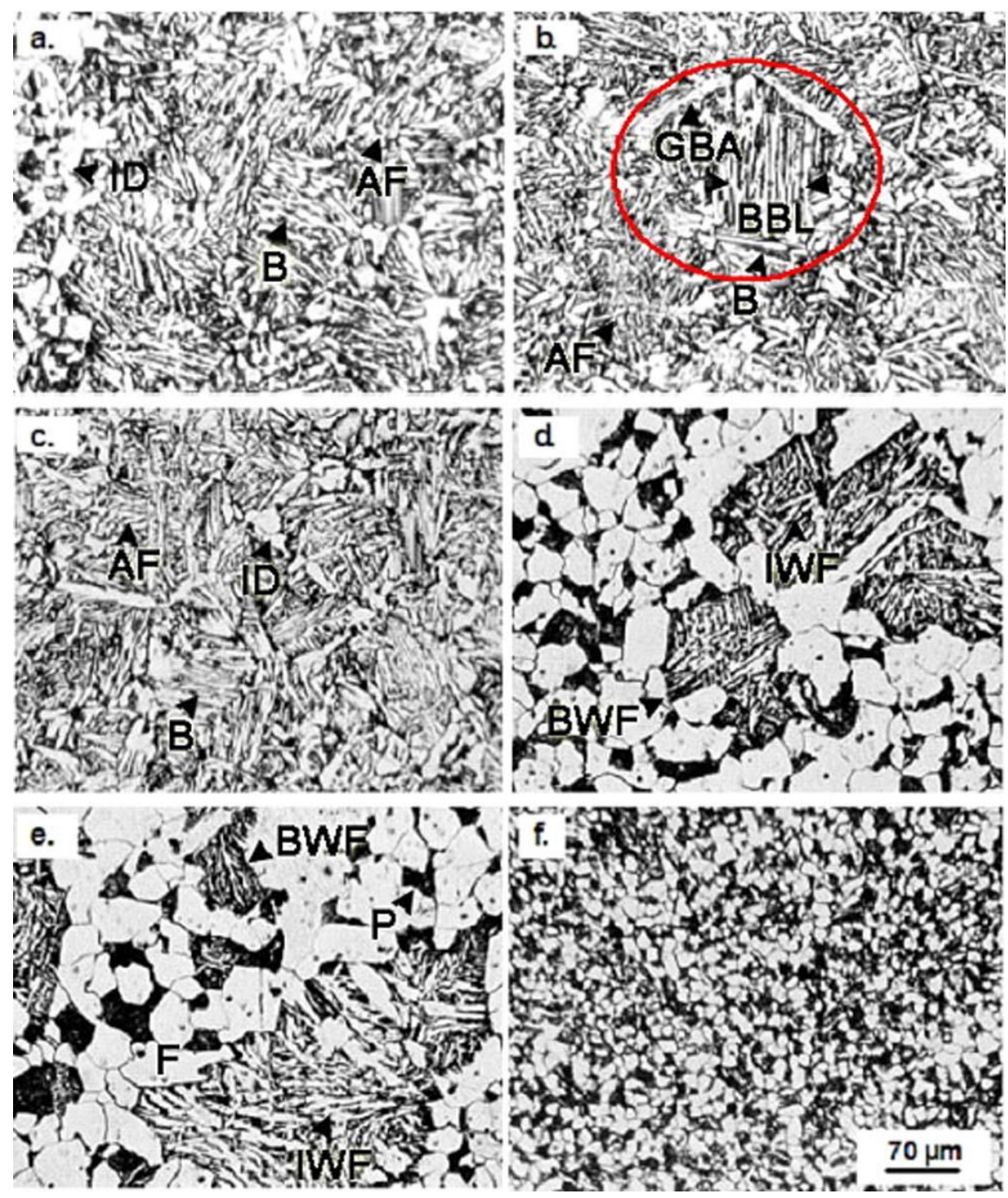

Fig. 6 Microstructures of different sections of side $\boldsymbol{F}$ of segment $\boldsymbol{A}$. a. and b. section 1A;c. section 2A; d. and e. section 3A; f. section 4A; (see Fig. 3b). B-bainite; IDidiomorphic ferrite; $A F$-acicular ferrite; ring denotes a previous austenitic grain; $G B A-$ grain boundary allotriomorphic ferrite; $B B L$-bundles of bainitic laths; $F$-ferrite; $P$ pearlite; IWF-intragranular Widmanstätten ferrite; BWF-block of Widmanstätten ferrite. 
Acicular ferrite and bainite prevail in Figure 6a, although idiomorphic ferrite is also visible. Bundle of bainitic laths, formed within the previous austenitic grains [6], is present in the central part of section 1A (Fig. 6b). In addition, allotriomorphic grain boundary ferrite also appears in the microstructure, although the presence of a small amount of martensite cannot be excluded. A very similar microstructure exists in section 2A (Fig. 6c).

These results show that a portion of side $\mathbf{F}$ was at high temperature, i.e. in the single-phase austenitic $(\gamma)$ region (above temperature $A_{3}$ ). It is possible that at the moment of tube rupture this part of side $\mathbf{F}$ (sections $\mathbf{1 A}$ and $\mathbf{2 A}$ ) was exposed to a temperature higher than $870{ }^{\circ} \mathrm{C}$ (see position a in $\mathrm{Fe}-\mathrm{C}$ phase diagram, Fig. 7), and the rapid cooling by the cooling water produced the bainitic transformation. This structure is also present at room temperature.

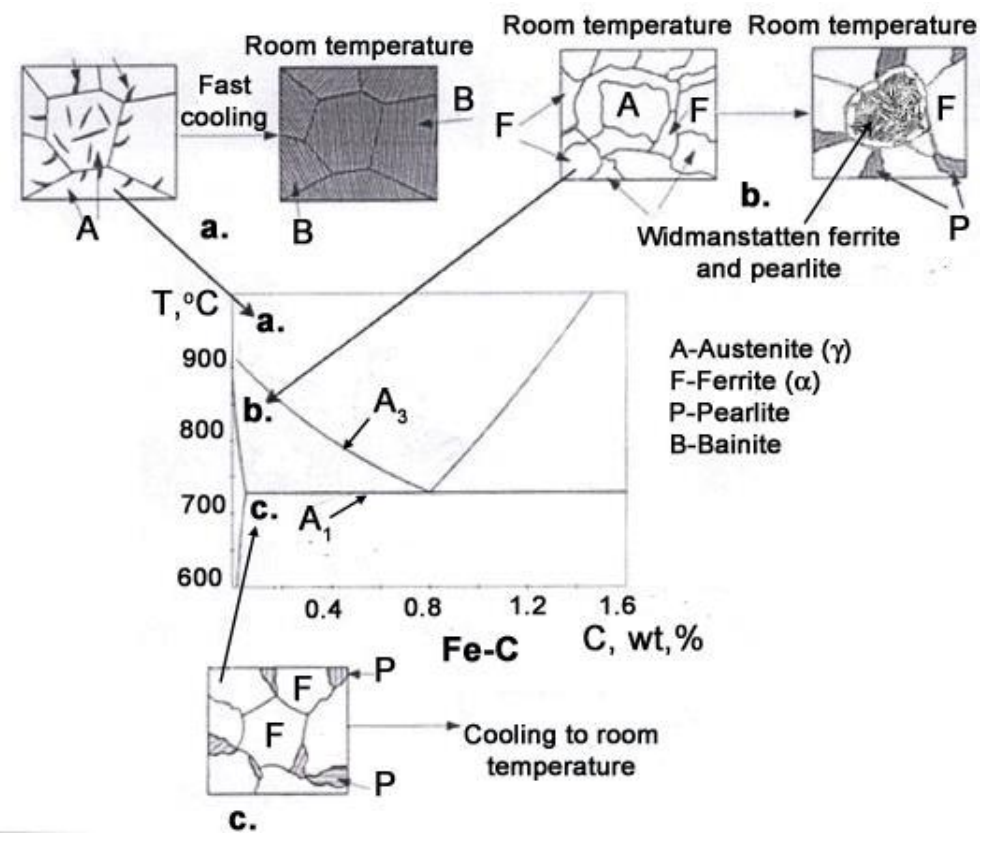

Fig. 7 Schematic presentation of expected microstructural features after cooling from different temperatures.

Microstructures of sections $\mathbf{3 A}$ and $\mathbf{4 A}$ differ from those of sections $\mathbf{1 A}$ and $\mathbf{2 A}$. Actually, the microstructure of section $\mathbf{3 A}$, except polygonal ferrite grains and pearlite, contains blocks in which ferrite has a characteristic morphology (Fig. 6d, e). This type of ferrite, known as intragranular Widmanstätten ferrite, is mostly formed within previous austenitic grains and appears in distinctive blocks [7, 8]. This structure suggests that the sample from section $\mathbf{3}$ was cooled with the relatively high rate from a temperature corresponding to the two-phase ferrite $(\alpha)+$ austenite $(\gamma)$ region, above the $A_{1}$ transformation temperature (position $\mathbf{b}$ in $\mathrm{Fe}-\mathrm{C}$ phase diagram, Fig. 7). In this region, the primary ferrite begins to develop inside the austenite grains. When the rupture of the tube occurred, water flooded the ruptured area and ferrite in some austenite grains quickly 
grew into some preferred orientations inside the grain forming laths and plates of Widmanstätten ferrite that tend to be aligned along the same direction within one grain [9]. Below $A_{1}$ temperature, the remaining austenite transforms into a fine and rather messy pearlite, and Widmanstätten block reaches its final morphology. Note that almost in each ferrite grain, at least one inclusion is visible. These inclusions serve as nucleation centers (seeds) for the formation of proeutectoid acicular ferrite in the region above the $\mathrm{A}_{3}$ transformation temperature [10]. The location of side $\mathbf{F}$, corresponding to section $\mathbf{4 A}$, is distinguished by completely different structure (Fig. 6f). A very fine-grained $(\sim 10 \mu \mathrm{m})$ ferritic-pearlitic structure may be seen. It may be supposed that a part of side $\mathbf{F}$ was exposed to a temperature in the high two-phase ferritic-pearlitic region (see position $\mathbf{c}$ in Fig. 7), and then was cooled at a higher rate, so the fine-grained structure was obtained.

In general, the entire range of microstructures of side $\mathbf{F}$ testifies to different temperatures and cooling rates at which individual sections of the tube were subjected. It should be emphasized that a variety of microstructures were formed in sections where mutual distances were less than one or two centimeters.

The average hardness of side $\mathbf{F}$ is $185 \mathrm{HV}$. The microhardness measurements would certainly reveal the difference in hardness between sections with different microstructural features.

A mixture of different microstructural features is typical for the whole crosssection of side BL (Fig. 8a-d).

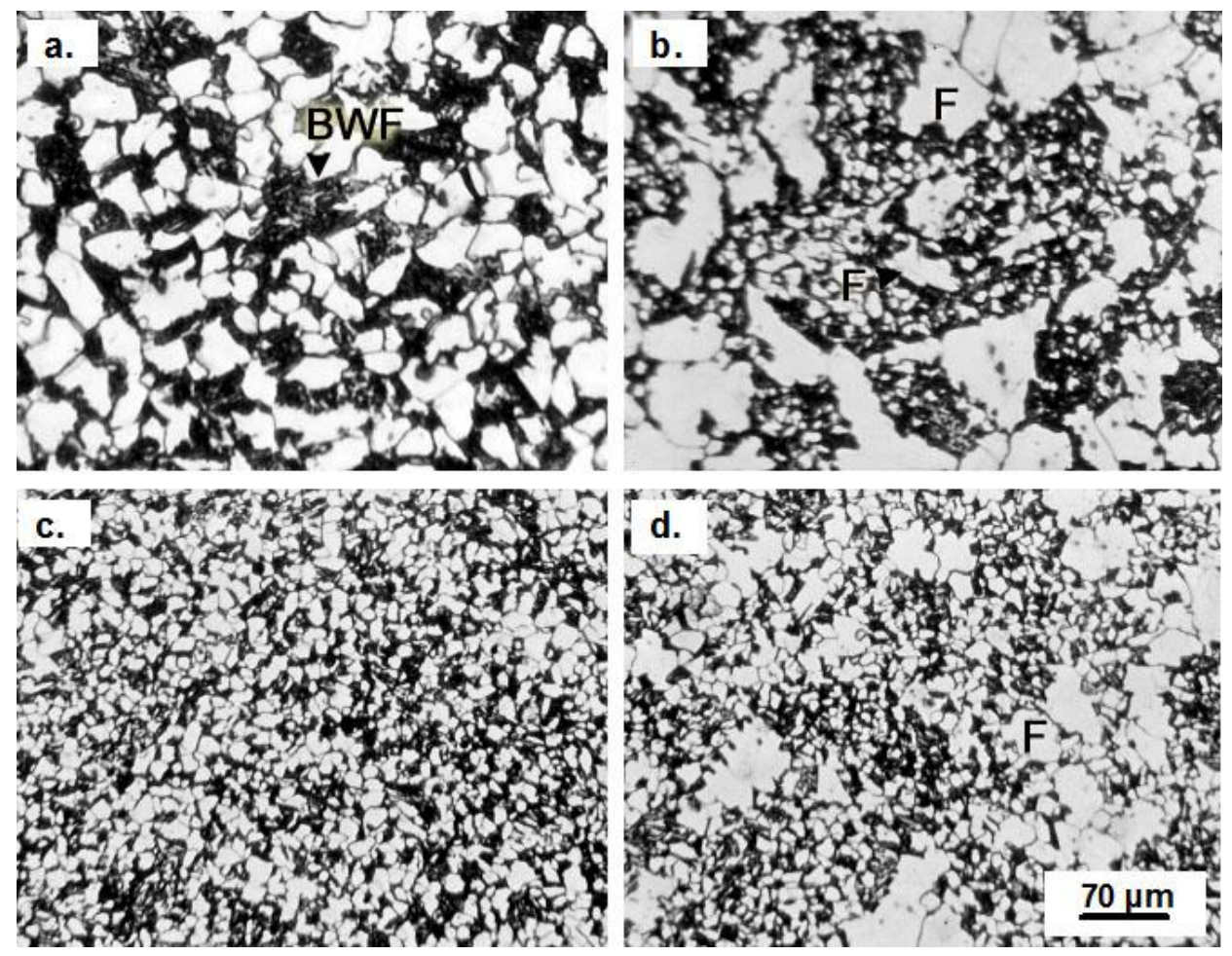

Fig. 8 Microstructures of different sections of side BL. a. and b. section $\mathbf{5 A}$; $c$ and $d$ section $7 A$ (see Fig. 3b). 
Islands of Widmanstätten blocks in the ferritic matrix appear in section $\mathbf{5 A}$ (Fig. 8a). However, a rather different structure consisting of coarse ferrite and a constituent which might be the remnant of previous massive Widmanstätten block may be seen in the same section. Platelets of small ferrite grains are formed inside this massive block (Fig. 8b). It is not always easy to distinguish these platelets from intragranular Widmanstätten ferrite or idiomorphic ferrite at an optical microscopy level. A very fine mixture of ferrite and pearlite in section 7A (Fig. 8c) is similar to the microstructure of side $\mathbf{F}$ (section $\mathbf{4 A}$, Fig. 8f). Coarse ferrite grains grow at the expense of pearlite (Fig. 8d).

The average hardness of side BL is $165 \mathrm{HV}$. Lower hardness and developed microstructures demonstrate that the whole side BL was exposed to lower temperatures than the most locations of section $\mathbf{F}$.

\section{Simulation of presumed temperature regime}

In order to estimate approximately the temperature at which $\mathbf{F}$ and $\mathbf{B L}$ sides were exposed, the samples (semi-segments) were annealed at 700, 800, 900 and $980{ }^{\circ} \mathrm{C}$. The temperature range from 900 to $980{ }^{\circ} \mathrm{C}$ (the single-phase austenitic region) was chosen to simulate temperatures at which, it was assumed, side $\mathbf{F}$ was exposed, whereas the temperature of $700{ }^{\circ} \mathrm{C}$ corresponded to presumed temperature for side BL. The annealing time was $1 \mathrm{~h}$ and air-cooling was performed. It was considered that the aircooling rate of small-sized samples approximately correlated to the rate at which the boiler tube was cooled when the cooling water penetrated into its rupture. It was also assumed that the temperature of cooling water was about $50{ }^{\circ} \mathrm{C}$.

Figures $9 \mathrm{a}$ and $\mathrm{b}$ show the microstructure after annealing at 980 and $900^{\circ} \mathrm{C}$, respectively. The bainitic structure of different forms is mostly present at these temperatures. After cooling from $980^{\circ} \mathrm{C}$ bainitic bundles are visible in Figure 9a, b. These structures are very similar to those of sections $\mathbf{1 A}$ and $\mathbf{2 A}$ Figure $6(\mathrm{a}-\mathrm{c})$, side $\mathbf{F}$. Taking into account possible difference in cooling rates between the massive tube and the small test-sample, it is difficult to determine whether portion of side $\mathbf{F}$ was exposed just to 900 or $980^{\circ} \mathrm{C}$, but similarity between simulated and examined structures cannot be denied. The microstructure of the sample annealed at $800^{\circ} \mathrm{C}$ contains Widmanstätten blocks, polygonal ferrite grains and pearlite (Fig. 9c). This structure, strongly resembling that of side F, section 3A (Fig. 6d, e), is assumed to originate from the two-phase ferrite-austenite region, possibly near $800^{\circ} \mathrm{C}$. Polygonal small-grained ferrite and pearlite (Fig. 9d) indicate that this structure, formed during annealing at $700{ }^{\circ} \mathrm{C}$, was cooled at a somewhat different rate than section $\mathbf{4 A}$, side $\mathbf{F}$ (Fig. 6f) and sections $\mathbf{5 A}$ and 7A, side BL (Fig. 8a, b). 
In any case, the results of previously described investigation and simulation proved a significant overheating of some parts of segment $\mathbf{A}$ of the boiler tube.
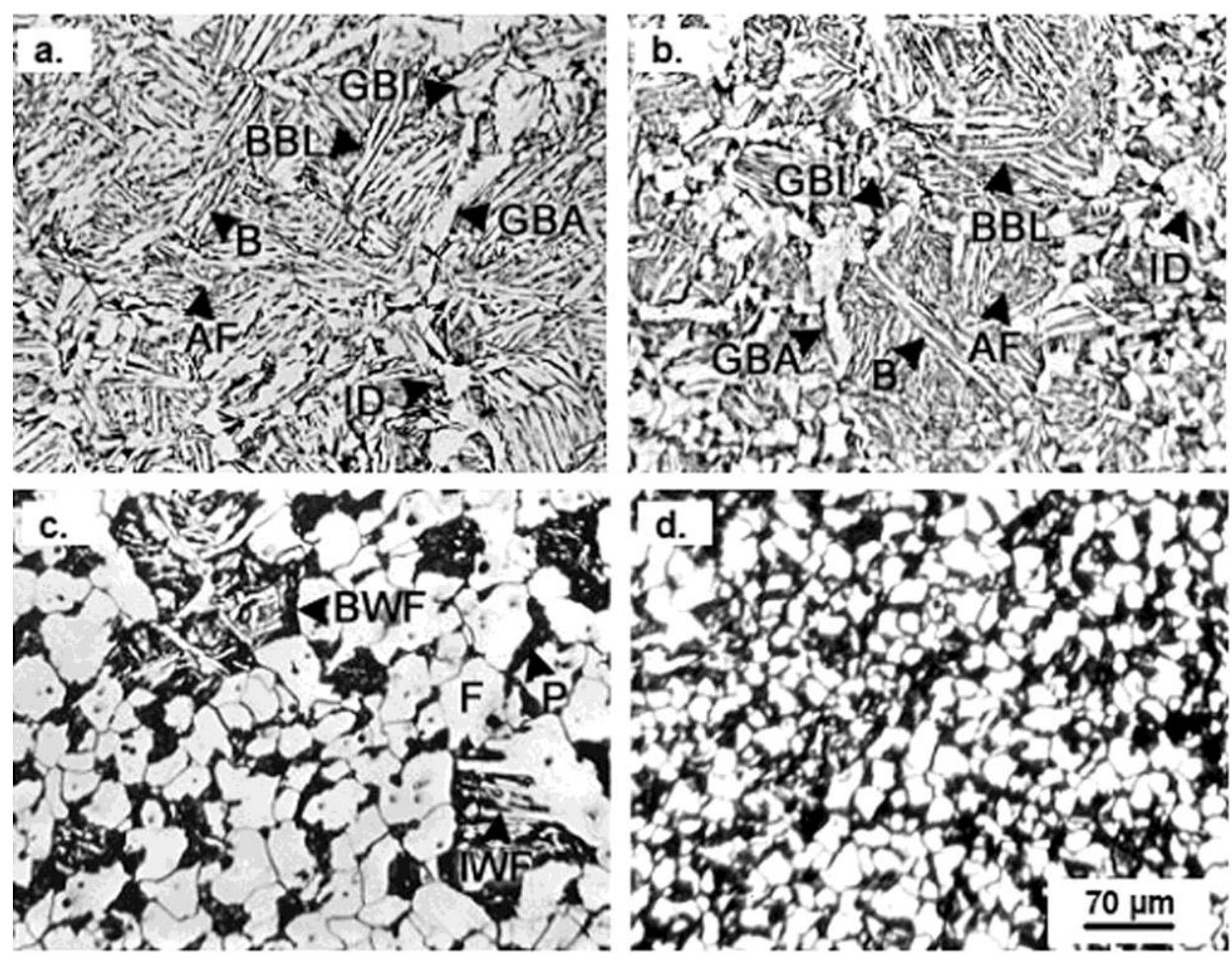

Fig. 9. Microstructures after annealing and air-cooling. $a, b, c$, $d$ are related to annealing temperatures at 980, 900, 800 and $700{ }^{\circ} \mathrm{C}$, respectively. GBI-grain boundary idiomorphic ferrite.

Microstructural investigation of segment $\boldsymbol{B}$

Microstructures of different sections of segment $\mathbf{B}$ are shown in Figure 10(a-d). 

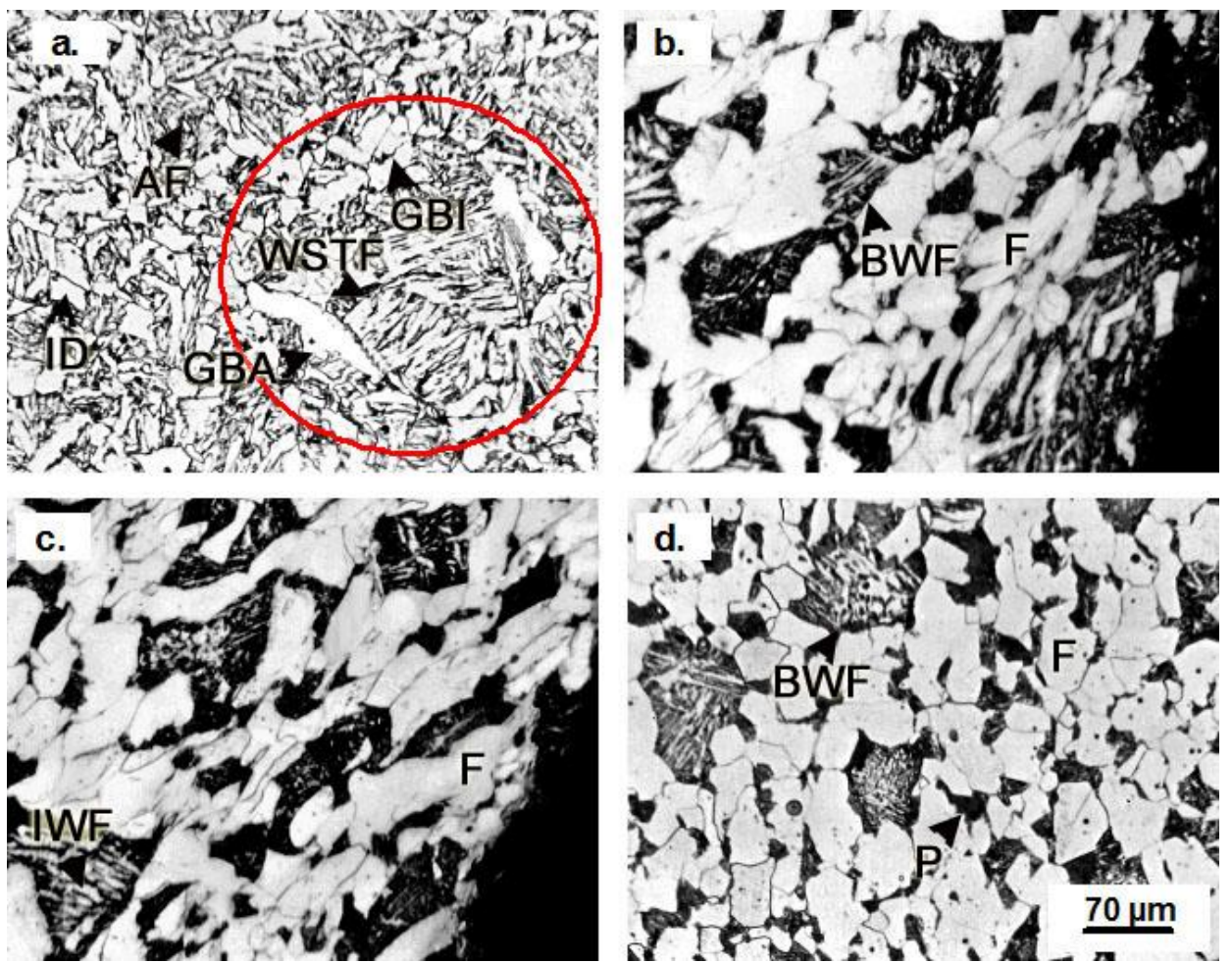

Fig. 10 Microstructure of different sections of segment $\boldsymbol{B}$. a. Side $\boldsymbol{F}$ (section 1 ); $b$. and c. side BL (section 2); d. side BL (section 3); (see Fig.3a); ring denotes a previous austenitic grain; WSTF-Widmanstätten saw teeth ferrite.

The microstructure is mostly composed of acicular ferrite and idiomorphic ferrite. Widmanstätten saw-teeth ferrite sideplates [11], nucleated directly at grain boundary allotriomorphs, could also be noticed inside the ring (Fig. 10a, section 1, side F). This structure is typical for a relatively high cooling rate from approximately $900^{\circ} \mathrm{C}$. Microstructure related to the opposite side of the tube is quite different and consists of large ferrite grains with some pearlite and Widmanstätten blocks (Fig. 10b, c, section 2, side BL). This structure, which is probably close to the fracture, might be the effect of rapid overheating between $A_{1}$ and $A_{3}$ temperature and subsequent quenching by cooling water [5], whereas the elongated shape of ferrite grains is the consequence of deformation occurred during fracture. Although the ferritic structure is somewhat depleted on pearlite, it does not imply that the process of decarburization might be active. The microstructure of section $\mathbf{3}$ is also to some extent, depleted on pearlite (Fig. 10d, section 3, side BL) indicating that a similar cooling rate was active in sections $\mathbf{2}$ and $\mathbf{3}$. These results show that a part of the segment $\mathbf{B}$, (section $\mathbf{1}$ ) side $\mathbf{F}$, was exposed to a higher temperature than sections $\mathbf{2}$ and $\mathbf{3}$, side $\mathbf{B L}$.

Summarizing a detailed microstructural investigation of segments $\mathbf{A}$ and $\mathbf{B}$ it is obvious that the material of the boiler tube was very inhomogeneous and that a variety of microstructures were formed during exploitation. Variations in heating temperatures and 
cooling rates, resulting in diverse microstructural features, are the main cause for the formation and multiplication of stresses leading to the rupture of the tube.

\section{SEM investigation of segment $\boldsymbol{C}$}

The objective of the SEM application was to investigate the basic fracture characteristics, and also a fracture mechanism. Since the oxide layer covered not only the walls of the tube but the fracture itself, it was almost impossible to determine the structural details of the fracture.

However, only a few microfractographs were successfully obtained and showed a pronounced brittle fracture of the boiler tube, irrespective of the segment location (Fig. 11a-d).
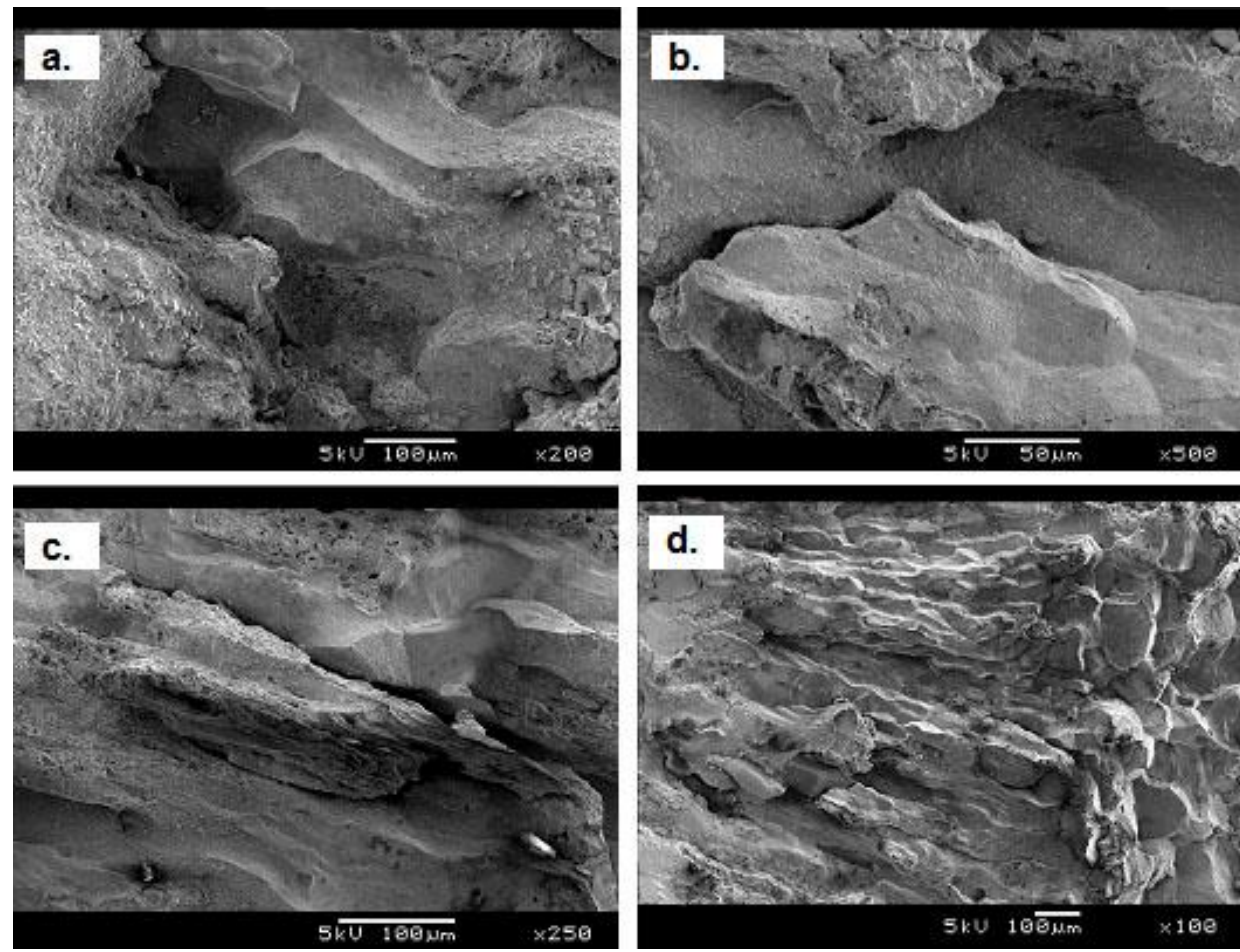

Fig. 11. SEM microfractographs of segment C. $a$ and $b$ section 1 ; $c$ and $d$ section 2.

\section{Conclusions}

Optical microscopy was used for a comprehensive microstructural characterization of the damaged boiler tube from the "Kolubara" electric power station. The objective of the research was to obtain not only data that should serve as the basic information on the parameters involved in damage but also in preventing such unwanted events.

The results of this investigation show that a variety of microstructures were formed in the material of the damaged boiler tube during its exploitation. Different microstructural features were detected at distances less than two centimeters.

The side of the boiler tube toward fire $(\mathbf{F})$ was exposed to severe overheating. In some local areas overheating was well above the $\mathrm{A}_{3}$ transformation temperature. The side 
toward boiler $(\mathbf{B L})$ was subjected to lower temperatures, in the region mainly between $\mathrm{A}_{1}$ and $\mathrm{A}_{3}$ temperatures. Simulation experiments confirmed the finding on the overheating of the $\mathbf{F}$ side.

Very limited SEM examinations revealed a pronounced brittle fracture of the boiler tube.

Results could not confirm that decarburization occurred in any section of the tube. The effect of hydrogen damage on the rupture of the tube could not be proven

Results could not confirm that decarburization occurred in any section of the tube. The effect of hydrogen damage on the tube rupture could not be proven.

The failure of the tube and formation of the hole in the wall of the tube ("window" fracture) was most likely due to local overheating. Different parts of the tube were exposed to quite different temperatures ranging from well above $\mathrm{A}_{3}$ to below $\mathrm{A}_{1}$ transformation temperature. These local, or even sub-local, temperature discrepancies in conjunction with different cooling rates induced not only different microstructures, but initiated formation and multiplication of stresses leading to the failure of the tube.

\section{Acknowledgments}

This work was financially supported by the Ministry of Education, Science and Technological Development of the Republic of Serbia through the Project Nos.III45012 and ON174004. The authors are grateful to Ms. Ljiljana Mihajlović for the execution of the metallographic part of this investigation.

\section{References}

[1] S. Chaudhuri: Mat Sci Eng A, 432 (2006) 90-99.

[2] V. Sijacki Zeravcic, G. Bakic, M. Djukic, B. Andjelic: "The Challenge of Materials and Weldments, Structural Integrity \& Life Assessment”, International Monograph from 9th Int. Frac. Mech. School, Zlatni Pjasci, Bulgaria, Eds. S. Sedmak and Z. Radakovic, MF, DIVK, TMF, Gosa (2008), pp. 183-202.

[3] A. Malik, A. Mereoufer, S. Al-Fozan: J Failure Analysis, 15 (2015) 246-250.

[4] K. Ranjbar: Eng Failure Analysis, 14 (2007) 620-625.

[5] Metals Handbook, "Failure Analysis and Prevention", vol. 11, 9th Edition, American Society for Metals, Eds. G.W. Powell, S. E. Mahmoud, 1986, Metals Park, Ohio, USA.

[6] H. Bhadeshia. R. Honeycombe: "Steels: Microstructure and Properties". 4th Edition, Butterworth-Heinemann, 2017, Amsterdam.

[7] Dj. Drobnjak: Metalurgija-Journal of Metallurgy, 3 (1996) 107-130.

[8] R. Grewal, C. Aranas Jr, K. Chadha, D. Shahriari, M. Jahazi, J. Jonas: Acta Mat, 109 (2016) 23-31.

[9] L.C. Chang: Mat Sci Eng A, 368 (2004), 175-182.

[10] Dj. Drobnjak, A. Koprivica, in "Fundamentals and Applications of Microalloying of Forging Steels”, Eds. C.J. Van Tyne, G. Krauss and D.K. Matlock, TMS, 1996. Warrendale, USA.

[11] D. Glišić, N. Radović, A. Koprivica, A. Fadel, Dj. Drobnjak, ISIJ International 50 (2010) 601-606.

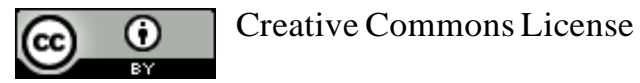

This work is licensed under a Creative Commons Attribution 4.0 International License. 